\title{
Tiroiditis subaguda: revisión a partir de un caso dínico
}

\author{
A. García de Francisco, C. Prieto Zancudo* \\ Residente de $3^{*}$ año de M edicina Familiar y Comunitaria. \\ * Especialista en Medicina Familiar y Comunitaria. \\ E.A.P. J azmín II. Área 4 Atención Primaria. INSALUD. Madrid
}

\section{RESUMEN}

La tiroiditis subaguda se conoce también con el término de tiroiditis granulomatosa o tiroiditis de Quervain, y se define como una inflamación de la glándula tiroidea secundaria probablemente a una infección viral. Es una entidad relativamente fre cuente $(5 \%)$ y constituye la causa más común de ti roides doloroso. La sintomatología inicial es de astenia intensa, malestar general y con frecuencia dolor en la zona tiroidea relacionado con la disten sión de la cápsula glandular ${ }^{1}$. Los hallazgos más destacables de las pruebas complementarias en la fase aguda son secundarios a la destrucción del parénquima glandular: elevación importante de la VSG (velocidad de sedimentación globular), au mento de las hormonas tiroideas (T4 L y T3 L), descenso notable de la TSH (hormona estimulante del tiroides) y una disminución de la RAIU (captación del I radiactivo por el tiroides). Cuando la sintomatología es leve, la administración de AINEs (antiinflamatorios no esteroideos) es suficiente para detener el proceso, sin embargo, en presencia de tirotoxicosis y síntomas intensos es necesario ad ministrar corticoides orales y betabloqueantes ${ }^{2}$. La evolución de la enfermedad puede ser de varios meses y generalmente no suele recidivar.

A continuación describimos el caso clínico de una mujer que acude a consulta por astenia, fiebre y dolor en la cara anterior del cuello de una semana de evolución, y posteriormente realizamos una revisión bibliográfica de la enfermedad.

Palabras clave: Tiroiditis. Tiroiditis subaguda de Quervain. Atención Primaria de salud.
Subacute thyroiditis: review in accordance with a clinical case

\begin{abstract}
Subacute thyroiditis is known also as subacute granulomatous thyroiditis or de Quervain's thyroi ditis, it's an inflammation of the thyroid gland of presumed viral aetiology.

It's a disorder non frecuently (5\%), but is the most common cause of a painful thyroid gland. The symptoms beginning with an intensive asthenia, malaise, and frecuently pain in the region of the thyroid gland secondary to distention of the gland capsule .

The most important laboratory data in the acute phase is the relation with the degree of thyroid damage caused: ERS (erythrocyte sedimentation rate) elevated serum leves of the T4 L and T3 L, elevated serum TSH (Thyroid-Stimulating Hormone) and low concentration to undetectable and depressed $R A I U$ (radioactive iodine uptake).

When the symptoms are not very intensive, are indicated drugs as NSAID (nonsteroidal anti-infla matory drugs), but in transient hyperthyroidism or more severe disease may be indicated beta blo ckers and oral steroids.

The disease progress in a few months, after retourning to normality and the relapse is rare . $^{3}$

Below we descibe the clinical case of a woman that attends to consultation by asthenia, fever and pain in the previous face of the neck on one week evolution; we accomplish a bibliographical review of the disease.
\end{abstract}

Key words: Thyroiditis. Subacute De Quervain's thyroiditis. Primary Health Care. 


\section{CASO CLÍNICO}

Mujer de 53 años que acude a consulta muy preocupada porque presenta desde hace 8 días fiebre de predominio vespertino de $38^{\circ} \mathrm{C}$, astenia intensa y aporta una analítica con alteración de la VSG (velocidad de sedimentación globular).

Previamente a las $48 \mathrm{~h}$ del inicio del cuadro, había visitado a un médico particular, el cual la exploró descartando patología grave y le solicitó una analítica. La paciente al recibir la analítica a los 6 días del inicio del cuadro, acude al centro de salud por la persistencia de los síntomas. En la analítica realizada se observa: hemograma con fórmula y recuento dentro de la normalidad, bioquímica general, perfil hepático y coagulación sin alteraciones y una VSG (velocidad de sedimentación globular) de $110 \mathrm{~mm} / 1^{\mathrm{a}} \mathrm{h}$. La enferma tiene síntomas intensos de ansiedad (angustia), por el miedo y sospecha de tener una posible neoplasia oculta, ya que su madre murió recientemente de cáncer de mama.

En la anamnesis además de los síntomas reseñados anteriormente, refiere molestias en la zona anterior del cuello y en ocasiones una sensación mal definida de presión o "vuelco" en la región precordial. No tiene ningún antecedente médico de interés, ni toma fármacos de forma habitual.

En la exploración física destaca:

-Nerviosismo y angustia.

- Hiperhidrosis en palmas.

-Frecuencia cardiaca: 90 latidos por minuto.

- Cabeza y cuello: arterias carótidas con latido normal y simétrico, exploración otorrinolaringológica sin hallazgos de interés, palpación de la cara anterior del cuello dolorosa, glándula tiroidea aumentada de tamaño con predominio del lóbulo derecho, el cual presenta a la palpación una consistencia heterogénea (rugosa).

-ACP (auscultación cardiopulmonar): murmullo vesicular conservado, latidos cardiacos no patológicos, sin soplos ni extratonos.

Se explica a la paciente que el proceso que presenta tiene características de corresponder a una enfermedad aguda, que puede ser debida a diferentes procesos: inflamación de la glándula tiroidea, infección vírica: VEB (virus de Epstein-Barr) o CMV (citomegalovirus), o el debut de alguna enfermedad autoinmune.

Se repite la analítica con: hemograma, VSG (velocidad de sedimentación globular), hormonas tiroideas: T3 L (triyodotironina) y T4 L (tiroxina) y TSH (hormona estimulante del tiroides).

Se inicia un proceso de I.L.T. (incapacidad laboral transitoria) por la sintomatología incapacitante que tiene la paciente.

Se realiza una aproximación diagnóstica de tiroiditis subaguda y como tratamiento se pauta inicialmente diclofenaco $50 \mathrm{mg}$ cada 8 horas, para controlar los síntomas.

\section{Evolución y seguimiento}

A los 10 días acude al centro de salud con las nuevas pruebas complementarias solicitadas y otras que aporta realizadas a petición de su médico privado. La paciente continua presentando sintomatología de MEG (malestar general), fiebre, nerviosismo, hiperhidrosis y astenia intensa, con escasa respuesta al tratamiento pautado (diclofenaco $50 \mathrm{mg}$ cada 8 horas). La exploración física no muestra ningún cambio respecto a la realizada previamente, excepto una frecuencia cardiaca de 98 latidos por minuto.

El resultado de las nuevas pruebas complementarias realizadas es el siguiente:

- Hemograma con fórmula y recuento sin alteraciones patológicas.

_VSG: $120 \mathrm{~mm} / 1^{\mathrm{a}} \mathrm{h}$.

-Hormonas tiroideas: T3 L (triyodotironina): 524,8 ng/dl, T4 L (tiroxina libre): $26,16 \mu \mathrm{g} / \mathrm{dl}$ y TSH (hormona estimulante del tiroides): 0,01 $\mu \mathrm{UI} / \mathrm{ml}$.

-Gammagrafía tiroidea según técnica convencional: se evidencia un bloqueo de la captación, sin que se logre visualizar parénquima tiroideo.

-Estudio inmunológico: anticuerpos antitiroglobulina $32 \mathrm{U} / \mathrm{ml}$ (rangos normales para el laboratorio $<60 \mathrm{U} / \mathrm{ml}$ ) y anticuerpos antimicrosomales $(\mathrm{TPO})<10 \mathrm{U} / \mathrm{ml}$ (rangos normales para el laboratorio $<60 \mathrm{U} / \mathrm{ml})$.

Se explica a la paciente que la enfermedad que presenta puede corresponder a una inflamación benigna de la glándula tiroidea de tipo subagudo y que la evolución es hacia la remisión total del cuadro en un periodo de tiempo entre 1-2 meses.

Se cambia el tratamiento farmacológico por la persistencia e intensidad de los síntomas: se administran corticoides orales (prednisona $40 \mathrm{mg}$ por las mañanas, descenciendo $5 \mathrm{mg}$ cada 3 días), y betabloqueantes (propanolol $10 \mathrm{mg}$ cada 8 horas) hasta nueva valoración clínica en una semana.

La paciente acude a la semana, comentando mejoría importante de los síntomas a las 48 horas de iniciar el nuevo tratamiento.

Se continúa con el descenso de corticoides de forma más rápida y a las dos semanas, se suprimen totalmente junto con los betabloqueantes.

Se repiten las pruebas complementarias al mes para valorar la respuesta al tratamiento y el resultado es el siguiente: hemograma sin cambios respecto al previo realizado, T4 L (tiroxina libre): 1,2 ng/dl, T3 L (triyodotironina): $2,1 \mathrm{ng} / \mathrm{dl}$, TSH (hormona estimulante del tiroides): $5 \mu \mathrm{UI} / \mathrm{ml}$, anticuerpos antitiroideos: negativos y gammagrafía tiroidea con una distribución del I radiactivo dentro de la normalidad.

\section{Proceso de diagnóstico diferencial realizado: discusión}

En nuestro caso, es importante señalar que el diagnóstico se realizó rápidamente porque la pa- 
ciente aportaba pruebas complementarias iniciales: hemograma, VSG (velocidad de sedimentación globular), bioquímica, perfil hepático, coagulación y posteriormente determinación de anticuerpos antitiroideos y gammagrafia tiroidea con yodo radiactivo.

El diagnóstico diferencial se realizó según el siguiente esquema:

- Por la sintomatología (astenia, fiebre, dolor en cara anterior del cuello) y VSG elevada.

Las patologías que se sospecharon inicialmente fueron: enfermedad viral aguda (mononucleosis infecciosa, citomegalovirus), polimialgia reumática con o sin vasculitis (arteritis de la temporal), inicio de una enfermedad del tejido conectivo: LES (Lupus Eritematoso Sistémico), dermatomiositis y enfermedad aguda de tiroides.

Los síntomas de angustia y nerviosismo podrían corresponder a un trastorno de ansiedad (trastorno de angustia por cancerofobia), o a un estado hipertiroideo. Se descartó un trastorno de angustia aislado, por el resto de síntomas presentes en la paciente y posteriormente por el resultado de las nuevas pruebas complementarias solicitadas.

- Por la exploración:

Se sospechó polimiagia reumática con o sin vasculitis (arteritis de la temporal), aunque no existía una correlación con los datos exploratorios: edad de la paciente y ausencia de signos más típicos (pérdida de fuerza en las cinturas de los miembros, arterias temporales engrosadas y sin latido).

La exploración otorrinolaringológica y glanglionar no se correspondía con una infección vírica de tipo mononucleosis infecciosa o citomegalovirus, aunque no se podía descartar hasta recibir el resultado de las $2^{\mathrm{a}}$ pruebas complementarias.

El inicio rápido de los síntomas y la ausencia de síntomas reumatológicos y cutáneos también descartaban una enfermedad del tejido conjuntivo, aún sin tener pruebas analíticas de confirmación (ANAS, ANOES).

La palpación dolorosa en la cara anterior del cuello y el aumento de la glándula tiroidea, hizo sospechar en patología tiroidea con clínica de hipertiroidismo (enfermedad de Graves-Basedow, bocio tóxico multinodular y tiroiditis con hipertiroidismo).

- Por las pruebas complementarias:

El dato de laboratorio que más hizo sospechar una tiroiditis subaguda y descartar el resto de las posibles tiroiditis (aguda bacteriana, tiroiditis silente en fase de hipertiroidismo, inicio de una tiroiditis crónica autoinmune de Hashimoto), fue el aumento importante de la VSG (velocidad de sedimentación globular): $120 \mathrm{~mm} / 1^{\mathrm{a}} \mathrm{h}$. La ausencia de anticuerpos antitiroideos, descartaba procesos como la tiroiditis de Hashimoto, Hashitoxicosis o la tiroiditis silente.

La disminución de la captación de I radiactivo en la gammagrafía tiroidea, era más compatible con tiroiditis subaguda, que con el resto de tiroiditis y de otras enfermedades tiroideas (enfermedad de Graves-Basedow y bocio tóxico multinodular).

\section{TIROIDITIS SUBAGUDA DE QUERVAIN}

La tiroiditis subaguda granulomatosa de Quervain, es una entidad que engloba un gran número de términos sinónimos como tiroiditis de Quervain, tiroididtis de células gigantes, tiroiditis granulomatosa, tiroiditis subaguda dolorosa o tiroiditis subaguda, aparece con frecuencia en el sexo femenino 3-5: $1^{4}$, y en la década de los 40-50.

\section{Etiología}

La causa más común de tiroiditis subaguda de Quervain es una infección viral del tiroides secundaria a una infección del tracto respiratorio superior.

Suele presentarse en brotes, con pródomos de tipo vírico y con una distribución estacional, más frecuente en verano y otoño.

Gracias a los cultivos virales en tejido tiroideo afecto, se han relacionado algunos de éstos como patógenos potenciales de esta enfermedad: adenovirus, coxackievirus, mononucleosis y virus de la gripe, virus de las paperas y echovirus ${ }^{5}$.

Por otro lado, parece que pudiera existir una mayor susceptibilidad genética a padecer la enfermedad en pacientes que presentan HLA-Bw 35 y HLA-DR3 ${ }^{6}$.

En algunos casos se ha objetivado la aparición de una autoinmunidad tiroidea transitoria (casi siempre en la fase aguda de la enfermedad), evidenciándose anticuerpos anti-antitiroidina peroxidasa (también denominados antimicrosomales), anti-tiroglobulina y anti-receptor de la TSH. Aunque se cree que el origen de dicha autoimunidad está más relacionada con la liberación de antígenos durante la inflamación que con un fenómeno primario ${ }^{7}$.

Existen muy pocos casos en la literatura de enfermedad de Graves tras episodio de tiroiditis subaguda $^{8}$.

\section{Histopatología}

El exámen histológico, que no es necesario para establecer el diagnóstico, se obtiene mediante la punción aspiración con aguja fina y revela inicialmente una destrucción del epitelio glandular, con infiltrados de polimorfonucleares y pérdida parcial o completa del coloide, con fragmentación y duplicación de la membrana basal. Posteriormente la lesión folicular se caracteriza típicamente por un nú- 
cleo central de coloide rodeado de células gigantes multinucleadas que finalmente progresarán a granulomas. Característicamente estas lesiones histológicas de la tiroiditis subaguda son reversibles.

\section{Manifestaciones clínicas}

El síntoma que con mayor frecuencia presentan los pacientes afectos de tiroiditis subaguda de Quervain es dolor en el cuello que se puede irradiar a oídos, occipucio, mandíbula y garganta.

La aparición del dolor puede ser de forma brusca o prolongarse varias semanas antes de sospechar el diagnóstico, pudiendo englobar a toda la glándula, un lóbulo o parte de un lóbulo.

Aunque el dolor sea inicialmente unilateral, normalmente en pocos días o semanas se extenderá hacia el lado contralateral.

Inicialmente, suele existir un síndrome prodrómico viral de vías respiratorias altas que incluye mialgias, febrícula, astenia, sensación de cuerpo extraño en garganta y disfagia.

En función del grado de destrucción del parénquima glandular pueden aparecer síntomas y signos de tirotoxicosis en la fase aguda $(50 \%$ de los casos), que suelen ser transitorios y suaves, pudiendo ir seguidos de un hipotiroidismo transitorio?.

En otras ocasiones la enfermedad se puede manifestar de forma menos típica como fiebre de origen desconocido, síndrome constitucional, simular una enfermedad inflamatoria crónica (como la arteritis de la temporal) o una enfermedad maligna y en los casos muy graves pueden debutar con síntomas obstructivos secundarios a la inflamación y el edema.

La palpación tiroidea normalmente revela un tiroides duro, doloroso y aumentado de tamaño, ya sea de forma difusa, unilateral o nodular. Generalmente la piel suprayacente suele encontrarse eritematosa.

\section{Pruebas complementarias}

El dato analítico más característico de la tiroiditis subaguda es una elevación importante de la VSG (más de $100 \mathrm{~mm}$ en la primera hora), lo que permite diferenciarla de otros tipos de tiroiditis; como tiroiditis crónica con tirotoxicosis transitoria "tiroiditis indolora o silente", tiroiditis crónica de Hashimoto y tiroiditis aguda microbiana ${ }^{10}$, en las cuales la elevación de la VSG no es tan intensa.

La serie blanca suele ser normal o ligeramente elevada y es frecuente la existencia de anemia normocítica normocrómica ${ }^{11}$.

La concentración de hormonas tiroideas $\mathrm{T}_{3} \mathrm{y} \mathrm{T}_{4}$ están elevadas debido a la inflamación glandular y destrucción folicular, provocando una descarga de dichas hormonas y un descenso de la TSH, pudien- do llegar a ser indetectable ${ }^{12}$. Se encuentra normalmente una elevación desproporcionada de $\mathrm{T}_{4}$ con respecto a $\mathrm{T}_{3}$.

Las pruebas de imagen y en este caso la gammagrafía tiroidea tiene más utilidad que en el resto de las enfermedades del tiroides. En la tiroiditis subaguda es típica la ausencia de visualización de la glándula tiroidea tras la realización de la gammagrafía con yodo radiactivo, por la destrucción del tejido secundario a la inflamación glandular. En la mayoría de los casos la captación es menor al 2\% en las primeras 24 horas $^{13}$.

El escáner tiroideo muestra una captación parcheada o muy baja del contraste (aunque si la enfermedad es localizada y los niveles de TSH no están muy disminuidos, puede objetivarse una única área afectada). Además puede proporcionar información evolutiva del proceso según los cambios en el patrón radiológico.

Otro dato a tener en cuenta es la ausencia en la mayoría de los casos de anticuerpos antitiroideos, aunque existen series de estudios que demuestran la presencia de ellos en un $2-5 \%$.

\section{Diagnóstico diferencial}

El diagnóstico diferencial debe realizarse inicialmente con aquellas patologías que asocien dolor en la cara anterior del cuello (Tabla I), procesos que asocien una VSG elevada y con el resto de tiroiditis (Tabla II). El diagnóstico diferencial de la tiroiditis subaguda y el resto de las patologías que pueden producir dolor en el cuello se realiza en función de las diferencias en el resto de la presentación clínica y de las pruebas complementarias.

Así por ejemplo, la presencia de una hemorragia aguda en el interior de una cisterna o un nódulo, suele manifestarse de forma más súbita que la tiroiditis subaguda, con dolor intenso cervical anterior unilateral y siempre sobre un nódulo tiroideo preexistente. Las técnicas de imagen (escáner con radioiodina) nos proporcionará el diagnóstico diferencial, ya que las zonas no afectas de la glándula presentarán función normal.

La tiroiditis aguda supurativa es extremadamente rara $^{14}$, y suele cursar con mayor leucocitosis y síndrome febril más llamativo que la tiroiditis subaguda. En esta patología la captación del trazador en la gammagrafía no suele estar disminuida, siendo la PAAF el procedimiento definitivo para el diagnóstico.

La tiroiditis de Hashimoto es fácilmente distinguible por la presencia, a títulos altos, de anticuerpos anti-tiroglobulina y peroxidasa tiroidea y la elevación de la serie blanca y de VSG mucho menos significativa que en la tiroiditis subaguda de Quervain.

La enfermedad de Graves se caracteriza por la presencia de RAIU normal o elevada, por lo que es difícil confundirlo con otras causas. 


\section{Tabla I}

DIAGNÓSTICO DIFERENCIAL DE CUELLO ANTERIOR DOLOROSO

Tiroiditis

Hemorragia aguda dentro de una cisterna

Hemorragia aguda dentro de un nódulo benigno 0 maligno

Carcinoma tiroideo de rápido crecimiento

Inflamación postradiación

Globus hystericus

Infección de quiste del conducto tirogloso

Infección de quiste de la hendidura braquial

Infección de higroma quístico

Adenitis cervical

Celulitis del cuello anterior

Amiloidosis

Infección por pneumocistis carinii

Tirotoxicosis secundaria a amiodarona

En el caso del carcinoma infiltrante del tiroides, aunque también pueda presentar dolor en región cervical por el rápido crecimiento y disminución de la captación del trazador, el resto de la clínica y los hallazgos de laboratorios hacen que raramente se confundan estas dos patologías.

El globus histericus es una reacción ansiosa caracterizada por una sensación de constricción laríngea que el paciente con frecuencia lo refiere como "un nudo en la garganta", relacionada con procesos de estrés emocional o ciclos menstruales. Se ha intentado relacionar este hecho con un mayor aporte sanguíneo a la glándula, sin haberse encontrado evidencia sobre este hecho, por lo que el diagnóstico será siempre de exclusión.

La amiloidosis tiroidea es una patología que puede cursar con clínica similar a la tiroiditis gra- nulomatosa, aumento importante de la VSG, disminución en la captación gammagráfica y respuesta espectacular a los corticoides, pero en estos casos suele existir afectación sistémica de la amiloidosis también ${ }^{15}$.

Existen fármacos antiarrítmicos ricos en yodo, como es la amiodarona, que pueden producir tirotoxicosis inducida por yodo (enfermedad de Jodbasedow) y con menor frecuencia tiroiditis. La historia clínica será clave para diagnóstico.

La infección por neumocisti carinii puede cursar con dolor en el cuello y baja captación en el trazador, pero la historia clínica al igual que en el caso anterior nos establecerá el diagnóstico.

Otras causas de tiroiditis pueden ser tiroiditis secundaria al tratamiento con interferón $\alpha 2 \mathrm{a}^{16} \mathrm{y}$ la tiroiditis postvacunal de la hepatitis $\mathrm{B}^{17}$.

\section{Evolución}

La evolución de este proceso es generalmente hacia la remisión espontánea en unos 4 a 6 meses ${ }^{18}$, presentando en su evolución más típica cuatro fases características:

-Fase aguda: caracterizada por la presencia de dolor tiroideo y tirotoxicosis, con una duración aproximada de 3 a 6 semanas.

-Periodo asintomático transitorio eutiroideo.

-Hipotiroidismo: puede ocurrir después de varias semanas y puede llegar a durar varios meses. En un 5\% de los casos, los pacientes pueden quedar hipotiroideos de forma permanente.

-Fase final de recuperación: en el que las pruebas funcionales tiroideas se normalizan.

Es una enfermedad, que generalmente no suele recidivar, aunque algunos autores han publicado en series de casos, que la recidiva se puede presentar en un $5 \%$.

Tabla II

DIAGNÓSTICO DIFERENCIAL DE LOS SUBTIPOS DE TIROIDITIS

\begin{tabular}{lcccccc}
\hline Subtipo & Etiología & Cuello doloroso & RAIU & TSH & T4 L & Ac. antitiroideos \\
\hline Tiroiditis de Hashimoto & Autoinmune & No & Variable & Variable & Variable & Presentes \\
T. Subaguda de Quervain & Viral & Sí & $\Downarrow$ & $\Downarrow$ & $\Uparrow$ & Ausentes \\
T. Linfocítica Silente & Autoinmune & No & $\Downarrow$ & $\Downarrow$ & $\Uparrow$ & Presentes \\
T. Aguda & Bacterias & Sí & Variable & Normal & Normal & Ausentes \\
Microbiana & Hongos & & & & & \\
Parásitos & & & & & \\
Hashitoxicosis & Autoinmune & No & $\Downarrow$ & $\Downarrow$ & $\Uparrow$ & Presentes \\
T. Fibrosa de Riedel & Desconocida & No & Variable & Normal & Normal & Variable \\
\hline
\end{tabular}

Slatosky J, Shipton B, Wahba H. Thyroiditis: Differential Diagnosis and Management. Am Fam Physician 2000; 61: 1074-52,1054. 


\section{Tratamiento}

El tratamiento inicial consiste en la administración de antiinflamatorios no esteroideos (ácido acetil salicílico 500-1.000 mg cada 8 horas) para disminuir el dolor tiroideo y el malestar general.

En ocasiones es necesario administrar corticoides orales (prednisona 20-40 mg cada 24 horas) cuando la sintomatología no cede con la toma de AINEs (antiinflamatorios no esteroideos), obteniéndose mejoría clínica posterior a las primeras 24 horas de su administración; si los síntomas no se resuelven después de 72 horas tras administrar los coerticoides orales, habría que pensar en otra etiología tiroidea.

El tratamiento corticoideo debe realizarse en pauta descendente hasta retirar en 2-4 semanas, para evitar la recurrencias (20\% de los casos).

Es importante no administrar inicialmente corticoides orales si el paciente no presenta una sintomatología muy intensa, ya que se han observado casos de aparición de tiroiditis autoinmunes con más frecuencia en las tiroiditis subagudas que fueron tratadas con corticoides orales, que las que solamente fueron tratadas con AINEs ${ }^{20}$.
La RAIU (captación de I radiactivo por el tiroides) puede ser de gran ayuda para la determinación de pacientes con riesgo de recaídas, por lo que en aquellos pacientes en los que la captación continúe siendo baja, se deberá prolongar la pauta de tratamiento corticoideo.

Los betabloqueantes son necesarios cuando los síntomas de hipertiroidismo son muy intensos. La pauta de propanolol es de $20-40 \mathrm{mg}$ cada 8 horas, durante 2-4 semanas.

No existe evidencia del beneficio del tratamiento con antitiroideos, ya que el mecanismo de esta enfermedad guarda más relación con la liberación de la prehormona tiroidea que con la síntesis de nuevas $\mathrm{T}_{3}$ y $_{4}$. Existen algunos casos publicados de la aparición de hipotiroidismo tardío, en aquellas tiroiditis subagudas en las que se administraron antitiroideos como tratamiento de base.

CORRESPONDENCIA:

Carmelo Prieto Zacundo

C/ Cobos de Segovia 7, portal 4, piso $5^{\circ} \mathrm{A}$

28005 Madrid

e-mail: cprieto@nexo.es

\section{Bibliografía}

1. Wartofsky L. Tiroiditis. En: Harrison TR, Fauchi A, Braunwald E, Isselbacher KJ, Wilson JD, Martin JB, et al. Principios de Medicina Interna. 14 ${ }^{\mathrm{a}}$ ed. Madrid: McGraw-Hill Interamericana, 1998; 2310-2.

2. Foz M. Tiroiditis. En: Farreras Rozman. Medicina Interna. $12^{\mathrm{a}}$ ed. Madrid: Doyma, 1992; (II): 2041-5.

3. Cano Pérez JF, Bundó Vidiella M. Disfunción tiroidea. Alteraciones del calcio. En: Martín Zurro A, Cano Pérez JF. Atención Primaria. Conceptos, organización y práctica clínica. $4^{\mathrm{a}}$ ed. Madrid: Harcourt Brace, 1999; (II):1390-4.

4. Litaka M†, Momotani N, Hisaoka T, Noh JY, Ishikaw N, Ishii $\mathrm{J} \dagger$, et al. TSH receptor antibody-associated thyroid dysfunction following subacute thyroiditis. Clinical Endocrinol Oxf 1998; 48: 445-53.

5. Farwel AP, Braverman LE. Inflamatory thyroid disorders. Otolaryngol Clin North Am 1996; 29 (4): 541-56.

6. Bennedbaek FN, Gram F, Hegedüs L. The transition of subacute thryroiditis to Graves' disease as evidenced by diagnostic imaging. Thyroid 1996; 6 (5): 475-9.

7. Slatosky J, Shipton B, Wahba H. Thyroiditis: Differential Diagnosis and Management. Am Fam Physician 2000; 61: 1047-52,1054

8. Meier DA, Nagle CE. Differential diagnosis of a tender goiter. J Nucl Med 1996; 37 (10):1745-7.

9. Bianda T, Schmid C. De Quervain's subacute thyroiditis presenting as painless solitary thyroid nodule. Postgrad Med J 1998; 74 (876): 602-3.

10. Hougton DJ, Gray HW, Mackenzie K. The tender neck: thyroiditis or thyroid abscess? Clin Endocrinol Oxf 1998; 48 (4): 521-4.
11. Schubert MF, Kounte DS. Thyroiditis. A disease with many faces. Postgrad Med J 1995; 98 (2): 107-8,112.

12. Kasagi K, Kousaka T, Misaki T, Iwata M, Sayeedul Alam M, Konishi J. Comparison of serum thyrotrophin concentrations determined by a third generation assay in patiens with various types of overt and subclinical thyrotoxocosis. Clinical Endocrinol Oxf 1999; 50: 185-90.

13. Hiromatsu Y, Ishibashi M, Miyake I, Nonaka K. Technetium$99 \mathrm{~m}$ tetrofosmin imaging in patients with subacute thyroiditis. Eur J Nucl Med 1998; 25 (10): 1448-52.

14. Collazos J, Geneva B. Bacterial sinsutis associated with subacute granulomatosis thyroiditis (letter). J Infect 1997; 634 (2): 158-9.

15. Kashyap AS, Mathew I, Kashyap S. A young woman with fever of unknown origin. Postgrad Med J 1995; 75 (886): 497-8.

16. Gonzalez-Fernandez B, Arranz A, Peñarrubia MJ, Menazuela M. Subacute thyroiditis associated with inteferon $\alpha 2$ a therapy (letter). Horm Metab Rev 1995; 27 (1): 45-6.

17. Toft J, Larsen S, Toft H. Subacute thyroiditis after hepatitis B vacination (letter). Endocr J 1998; 45 (1): 135.

18. Ghada Haddad MD. Is it hyperthyroidism? You can't always tell from the cinical picture. Postgrad Med J 1998; 104 (1): 42-59.

19. Litaka $\mathrm{M} \dagger$, Momotani $\mathrm{N}$, Ishii $\mathrm{J} \dagger$, Ito $\mathrm{K}$. Incidence of subacute thyroiditis recurrences after a prolonged latency: 24years survey. J Clin Endocrinol Metab 1996; 81 (2): 466-9.

20. Topuzovic N, Smofe J, Karner F. The therapeutic approach in subacute (de Quervain's) thyroiditis. J Nucl Med 1997; 38 (10): 1665 . 